\title{
La dificultad para difundir los trabajos científicos, patrimonio de la comunidad
}

Julio Fabián Merlo | Facultad de Ciencias Sociales de Olavarría, Universidad Nacional del Centro de la Provincia de Buenos Aires

URL de la contribución <www.iaph.es/revistaph/index.php/revistaph/article/view/4679>

Una de las preguntas que surgen a los que realizan investigaciones es ¿cómo difundir nuestra investigación a un público amplio y al mismo tiempo para nuestros colegas? Muchas veces, hacerlo por canales distintos implica un doble esfuerzo que, en mucho de los casos, no logra cubrir nuestras expectativas. Una forma de resguardar y difundir la producción es mediante los repositorios que ofrece la institución donde se trabaja (universidad, institutos de investigación, etc.). La experiencia de nuestro lugar de trabajo, Facultad de Ciencias Sociales de Olavarría UNICEN (Buenos Aires, Argentina), es que los repositorios se ubican en las unidades académicas de la universidad. Esto implica que, para acceder a alguna información de interés, uno debe ingresar palabras claves en un buscador (Google) y lograr entrar al repositorio.

La página de internet de la universidad tiene una central con un link que deriva a cada página de la unidad académica donde se encuentran los repositorios de cada disciplina. No hay un link que permita entrar a los reser-
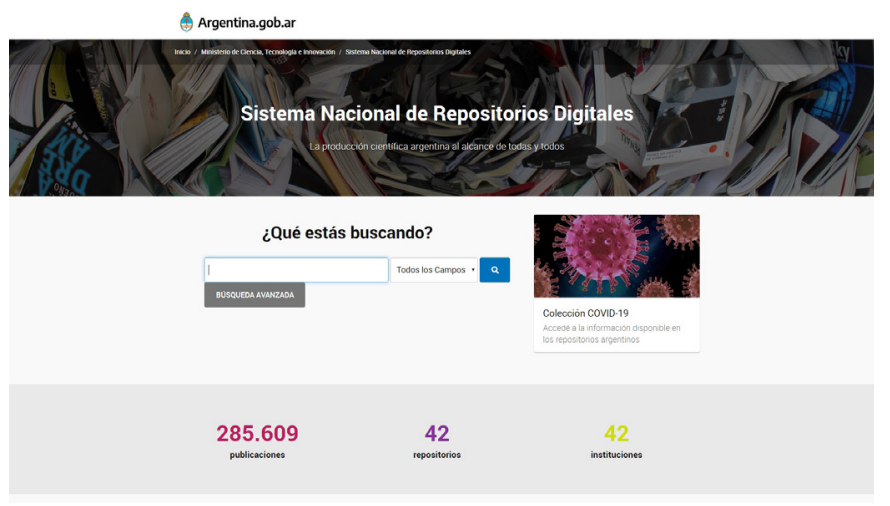

SNRD: la producción científica argentina al alcance de todos vorios de manera directa y se requiere de un buscador para poder acceder a algún trabajo específico. En cambio, si se ingresa en un buscador palabras claves de algún tema específico, de manera directa aparecen las plataformas ResearchGate, Academia.edu, entre otras. Estas redes facilitan el acceso a los artículos y a la producción científica, permiten la generación de vínculos e intercambio con otros colegas de la misma disciplina $u$ otras y, además, se actualizan sencillamente. Incluso en el patrimonio pre y posthistórico de los lugares donde efectuamos investigación, existen muchos colaboradores aficionados que aportan datos a la investigación. Se puede hacer transferencia de información que los reservorios no permiten, ya que estos son cargados a la página de la universidad y quedan estáticos en el lugar a la espera de visitas.

Las plataformas comerciales tienen como objetivo principal la venta de publicidad y su promoción. Cuando uno se suscribe, envían una publicación al mail, asiduamente se reciben artículos y publicaciones, sin la necesidad de que uno los tenga que buscar. Podemos recibir información de investigaciones recientemente terminadas científicamente diversas. La desventaja de estas plataformas es el flujo de circulación de la producción científica en un mundo globalizado y no se logra procesar toda la información.

Un ejemplo es la pandemia del Covid-19; los medios de comunicación divulgan diferentes versiones del origen, de esta manera se diluye la realidad. Los repositorios institucionales que solo almacenan la producción de los miembros investigadores no cuentan con un mecanismo de promoción de lo que se conserva en su plataforma. En este punto es donde las plataformas comerciales pre- 
a debate Repositorios y redes sociales académicas para la transferencia del conocimiento abierto

| coordina Remedios Melero Melero

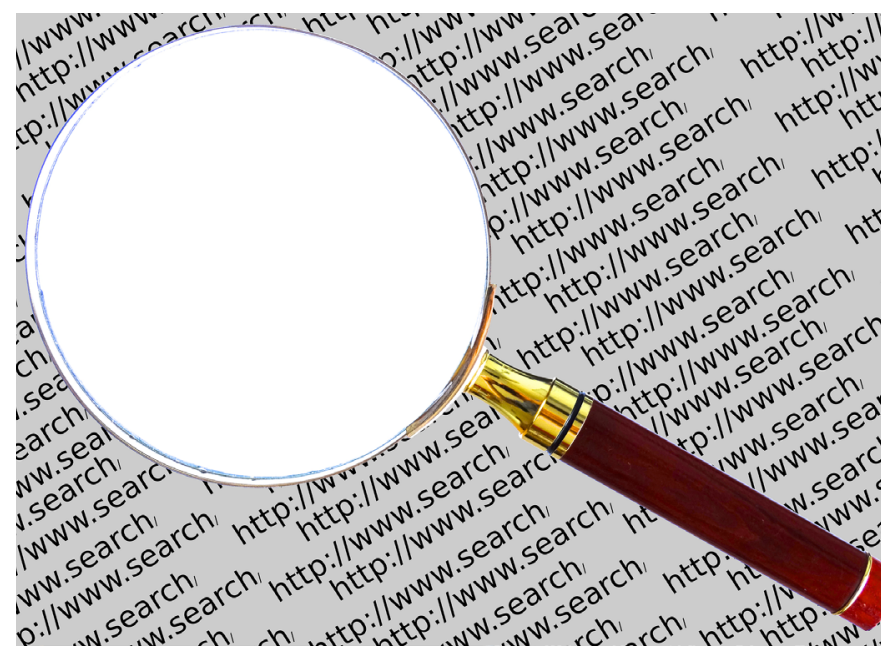

La divulgación de trabajos científicos relacionados con el patrimonio cultural debe ser en un espacio abierto y de alcance para darles visibilidad

sentan ventajas. Retomando el ejemplo de la pandemia, si investigadores inventaran una vacuna para el Covid19 y fuera puesto en un repositorio, ¿quién se entera? Pero si fuera publicado en una plataforma comercial, se difundiría rápido y masivamente. Con las producciones científicas que se pueden generar pasaría lo mismo.

La divulgación de trabajos científicos relacionados con el patrimonio cultural debe ser un espacio abierto y de alcance a la comunidad en diferentes plataformas. Esto tiene variables a favor; se puede difundir el patrimonio a la sociedad local, a otros investigadores y a personas del otro lado del mundo. De esta manera no queda invisibilizado por el flujo de información de los medios multinacionales. Otro punto a tener en cuenta es que el mayor alcance de trabajos de investigación posibilita el intercambio y entrecruzamiento de datos.

Es importante que se dé la divulgación de forma responsable, al igual que en los repositorios académicos, para evitar el plagio y mostrar de forma clara las fuentes de donde se extrae la información. Si una publicación sale en la plataforma $A$ y luego en la $B$, ambas deben aclarar dónde están publicadas. Generalmente los que manejan repositorios o tienen acceso a él son colegas. Dado que los reservorios no difunden sus producciones como lo hacen las plataformas comerciales abiertas, es frecuente el uso de la información de los repositorios sin que se citen a los autores, o el robo de ideas, hipótesis y datos. Mucho de estos trabajos plagiados son volcados a plataformas abiertas, donde en la megaproducción de paper pasan desapercibidos. Este enorme volumen de información es uno de los inconvenientes que tienen las plataformas abiertas, incentivadas por la producción científica "exprés" que exigen las agencias de investigación nacionales (en Argentina: AGENCIA y CONICET), cuyo requisito son dos publicaciones por año para cumplir con la producción científica, que luego serán controladas por los datos básicos, independientemente de si la producción lograda es relevante o no.

Los repositorios deben tener una plataforma que realmente garantice el uso de la información con autorización de quien la generó. Un sistema de visibilización sin la necesidad de que cada investigador tenga que hacerse cargo de la difusión y al mismo tiempo interactuar con pares de distinta formación. Sucede que la producción puede ser realizada por una disciplina que complementa o aporta metodología, datos e interpretaciones a otras ciencias. Este punto es fundamental para lograr trabajos interdisciplinarios que enriquecen el objeto de estudio.

Son variadas las causas de la baja producción en ciencias sociales y humanas guardada en repositorios o redes sociales científicas. Estas responden a diferentes orígenes que van desde la informalidad hasta lo económico. Los presupuestos para producción científica son escasos; más de un investigador produce aportando de su patrimonio privado, lo que restringe los recursos para trabajar. Esta situación genera poca motivación en los investigadores y para las nuevas generaciones, dando pie a la producción informal. El patrimonio histórico arqueológico, entre otros, no es abordado, con mucha frecuencia, por profesionales sino por aficionados. Que no está mal, si lo realizan respetando las normas legales, de otra forma, muchos de esos registros materiales, como los arqueológicos y paleontológicos, se perderían. El problema está en que el material recuperado por un entusiasta sea difundido a la sociedad 
de manera correcta y no se use como un bien económico (como la venta ilegal de fósiles, documentos, artefactos, para particulares o museos privados) o que se generen leyendas que no tienen contrastación empírica. Un ejemplo, de la zona donde trabajo, es el caso de los túneles del Fuerte Independencia de la ciudad de Tandil. Historiadores autodidactas durante décadas sostuvieron que el Fuerte Independencia de 1823 (Orígenes de la Ciudad) tenía túneles para protegerse de los malones que realizaban los "indios" (saqueos y la toma de mujeres y niños cautivos). Cuando desde la academia, historiadores y arqueólogos, empezamos a investigar, concluimos que los "malones indios" no pasaron por el lugar y arqueológicamente, hasta el momento, nunca encontramos un túnel relacionado con la fortificación, entre otros sucesos.

La experiencia en este tipo de intercambios informativos es diferente. He presentado trabajos a dos repositorios; uno es el de mi institución, que está a cargo de un colega, donde suben algunos de los artículos o tesis de doctorado. Aquí, acceder a algún artículo no es fácil. Mi otra experiencia es en un repositorio universitario, donde los creadores de la plataforma apuestan por lograr la mayor divulgación, respetando y dando a conocer quiénes son los que generan la información y la posibilidad del intercambio, hecho que me ha permitido realizar intercambios científicos y sociales. 